\title{
SPECIAL SECTION \\ 2D BUT NOT 3D: PICTORIAL-DEPTH DEFICITS IN A CASE OF VISUAL AGNOSIA
}

\author{
Oliver H. Turnbull ${ }^{1}$, Jon Driver ${ }^{2}$ and Rosaleen A. McCarthy ${ }^{3}$
}

$\left({ }^{1}\right.$ School of Psychology, University of Wales, Bangor, UK; ${ }^{2}$ Institute of Cognitive Neuroscience and Department of Psychology, University College London, UK; ${ }^{3}$ Department of Experimental Psychology, University of Cambridge, UK)

\begin{abstract}
Patients with visual agnosia exhibit acquired impairments in visual object recognition, that may or may not involve deficits in low-level perceptual abilities. Here we report a case (patient DM) who after head injury presented with objectrecognition deficits. He still appears able to extract 2D information from the visual world in a relatively intact manner; but his ability to extract pictorial information about 3D object-structure is greatly compromised. His copying of line drawings is relatively good, and he is accurate and shows apparently normal mental rotation when matching or judging objects tilted in the picture-plane. But he performs poorly on a variety of tasks requiring 3D representations to be derived from $2 \mathrm{D}$ stimuli, including: performing mental rotation in depth, rather than in the picture-plane; judging the relative depth of two regions depicted in line-drawings of objects; and deciding whether a line-drawing represents an object that is 'impossible' in 3D. Interestingly, DM failed to show several visual illusions experienced by normals (Muller-Lyer and Ponzo), that some authors have attributed to pictorial depth cues. Taken together, these findings indicate a deficit in achieving 3D intepretations of objects from 2D pictorial cues, that may contribute to object-recognition problems in agnosia.
\end{abstract}

Key words: pictorial depth, agnosia, object recognition, 2D, 3D

\section{INTRODUCTION}

The period spanned by Ennio De Renzi's inspirational career has seen an enormous growth in our understanding of vision and its neurobiological basis, due in part to single-cell recording methods and more recent technical developments such as functional imaging, but also due to the careful study of neuropsychological deficits after brain injury in neurological patients, as pioneered by De Renzi. As regards theory, the recent decades also have seen an increasing understanding of the importance of regional specialization - in domains such as spatial cognition, object recognition, and visually-guided action (Farah, 1990; Grusser and Landis, 1991; Milner and Goodale, 1995), together with an understanding that small-scale 'modules' are typically part of wider patterns of cortical organization, and form interacting components of widespread networks (Milner and Goodale, 1995; Ungerleider and Mishkin, 1982; see also Cowey, 1981). De Renzi has of course made seminal contributions to virtually every domain of neuropsychology alluded to above, across several decades (e.g. De Renzi and Faglioni, 1967, to De Renzi and Di Pellegrino, 1998) - though his work is perhaps most accessibly known from his classic monograph (De Renzi, 1982)

The extent of progress in understanding the neuropsychology of vision has been far from uniform, however, and there are several apparently important topics that may have been underinvestigated to date. One such topic is visual depth perception: and in particular the question of how three dimensions are extracted from twodimensional images. There is an extensive psychological literature on this topic (Gibson, 1966; Gregory, 1966; Julesz, 1971; Rock, 1973), but rather less in the way of neuropsychology (see Carey et al., 1998). De Renzi's (1982) classic text covers the issue of depth perception in only two brief sections (pp. 60-63 and pp. 141-145). Nevertheless, in reviewing the literature two decades ago, De Renzi characteristically foreshadowed a number of issues that have since become more widely recognised (e.g. Turnbull, 1999). For example, De Renzi warned of the potential risks of designating disorders as being of exclusively perceptual origin, when the findings might also involve motor processes, as when a 'depth' deficit is evident only in action (e.g. in distance errors when misreaching, De Renzi, 1982, p.141).

De Renzi (1982) also commented on the likely anatomy of disorders in depth processing. He noted (pp.141-145) that the most common lesion sites implicated by these deficits seemed to involve the occipital and/or parietal lobes (i.e. including dorsal rather than ventral pathways). The more recent literature, as reviewed by Carey et al. (1998), contains only a limited number of neuropsychological studies on depth, which mainly approached the problem from the 'perception versus action' perspective of Milner and Goodale (1995), and have focused primarily on the dorsal 'visuo-motor' stream. Thus, recent studies have tended to focus on the role of depth information in the processing of relative or absolute distance, as 
evidenced in either perceptual judgements or else in the biomechanics of reaching, grasping and catching, with binocular versus monocular cues being compared (see Haffenden and Goodale, 1999; Mon-Williams and Dijkerman, 1999; Marotta et al., 1997; Mon-Williams et al., 2001; Servos et al., 1992; Servos and Goodale, 1998). The main thrust of this literature has been in general agreement with De Renzi's (1982) proposal that binocular depth information may be useful in the control of spatial action (see also Dijkerman et al., 1996; Gallese et al. 1995, Otto-de Haart et al., 1999, Marotta et al., 1998), by the dorsal stream. Any possible role for pictorial cues to depth processing in the ventral (occipito-temporal) stream appears to have been less studied by neuropsychologists in recent years, at least within the literature inspired by the dorsal/ventral dichotomy. However, in mainstream psychology it has often been argued that pictorial cues to distance might have major impacts on perceptual processes, as in size-constancy (e.g. Gibson, 1966) and in potentially related illusions of size (e.g. Gregory, 1966).

We turn now to consider the possible role of pictorial depth-cues in 'visual agnosia', the generic term for acquired neurological disorders of object-recognition (see Farah, 1990; Grusser and Landis, 1991; Humphreys and Riddoch, 1987 for reviews). Some forms of brain-damage (typically affecting occipito-temporal cortex, in the ventral stream) can disrupt visual object recognition, while leaving 'elementary' vision (brightness, acuity, colour, motion) fairly intact. Recognition by touch, sound, or verbal description may also be preserved (see De Renzi, 1982; Farah, 1990; Grusser and Landis, 1991). Many patients diagnosed on this basis as suffering from visual agnosia are described as apparently having access to a fairly accurate description of the structural properties of the visual objects before them, which they cannot recognise. Lissauer (1890) originally distinguished between 'apperceptive' disorders (for patients in whom there was some fundamental perceptual deficit in perceiving shape, as apparent for instance in their inability to match or copy simple shapes), versus those with 'associative' impairment, in whom low level perception was apparently intact. Teuber (1968) elegantly described associative agnosics as having "a normal percept stripped of its meaning". However, it has since been argued that many patients who would classically have been diagnosed as associative agnosics may in fact have subtle 'high-level' perceptual impairments that disrupt the full extraction of object structure (e.g. see Farah, 1990; Humphreys and Riddoch, 1987; Farah and Feinberg, 1997). It has also been noted by such authors that the traditional clinical test for intact structural perception in agnosic patients - namely a preserved ability to make accurate copies of seen line-drawings - may be inadequate.

It was in this context that Farah (1990, pp. 5969) listed several lines of evidence which suggested that many cases of so-called 'associative' agnosics might in fact have some perceptual deficits in extracting object structure, despite preservation of elementary visual processes. While such patients may eventually produce relatively accurate copies of line drawings, in fact these may be produced in a pathologically 'slavish' and piecemeal manner (see also Humphreys and Riddoch, 1987). Moreover, one patient categorised as having associative visual agnosia (with apparently 'normal' copying) case M.S. of Ratcliffe and Newcombe (1982), was unable to classify linedrawings of the type introduced by Penrose and Penrose (1958) as 'possible' or 'impossible' in 3D. The 'impossible' versions among these stimuli depict perspective views which are very unlikely (Gregory, 1970) to correspond to a coherent threedimensional object, because of inconsistencies in the pictorial depth information at various junctions on the shape (Cowan, 1974). We report a task based on such stimuli later in this paper (and an example can be observed in Figure 6). Distinguishing possible and impossible versions of these stimuli is trivial for normal observers, but this distinction was problematic for patient MS (Ratcliffe and Newcombe, 1982). Moreover, MS apparently took the same amount of time to copy both possible and impossible nonsense objects (Farah, 1990, p.63), whereas normal subjects are considerably faster to copy the possible objects, presumably as they can use the cues from coherent 3D structure to aid them.

Thus some patients with agnosic deficits, including some of those who would traditionally be classified as 'associative' on the basis of relatively preserved copying, may be restricted in their ability to obtain the appropriate $3 \mathrm{D}$ structure from the 2D cues available in line-drawings. Perhaps patients such as MS are able to extract $2 \mathrm{D}$ edge-based information in the image while the extraction of 3D structure from pictorial cues within the $2 \mathrm{D}$ image might be impaired. If so, this might demonstrate one form of spatial processing that might be specific to the representation of objects, having little or nothing to do with the various forms of 'depth' processing that have been associated with the dorsal stream in studies of visually-guided action (c.f. Carey et al., 1998).

In the remainder of this paper, we report the new case of a patient (DM) who suffers from visual agnosia following head-injury. He still appears able to extract stable 2D information from visual images; but his ability to extract 3D structure from the pictorial depth-cues within 2D images (e.g. line-drawings) is greatly compromised. This deficit in deriving $3 \mathrm{D}$ structure from pictorial 


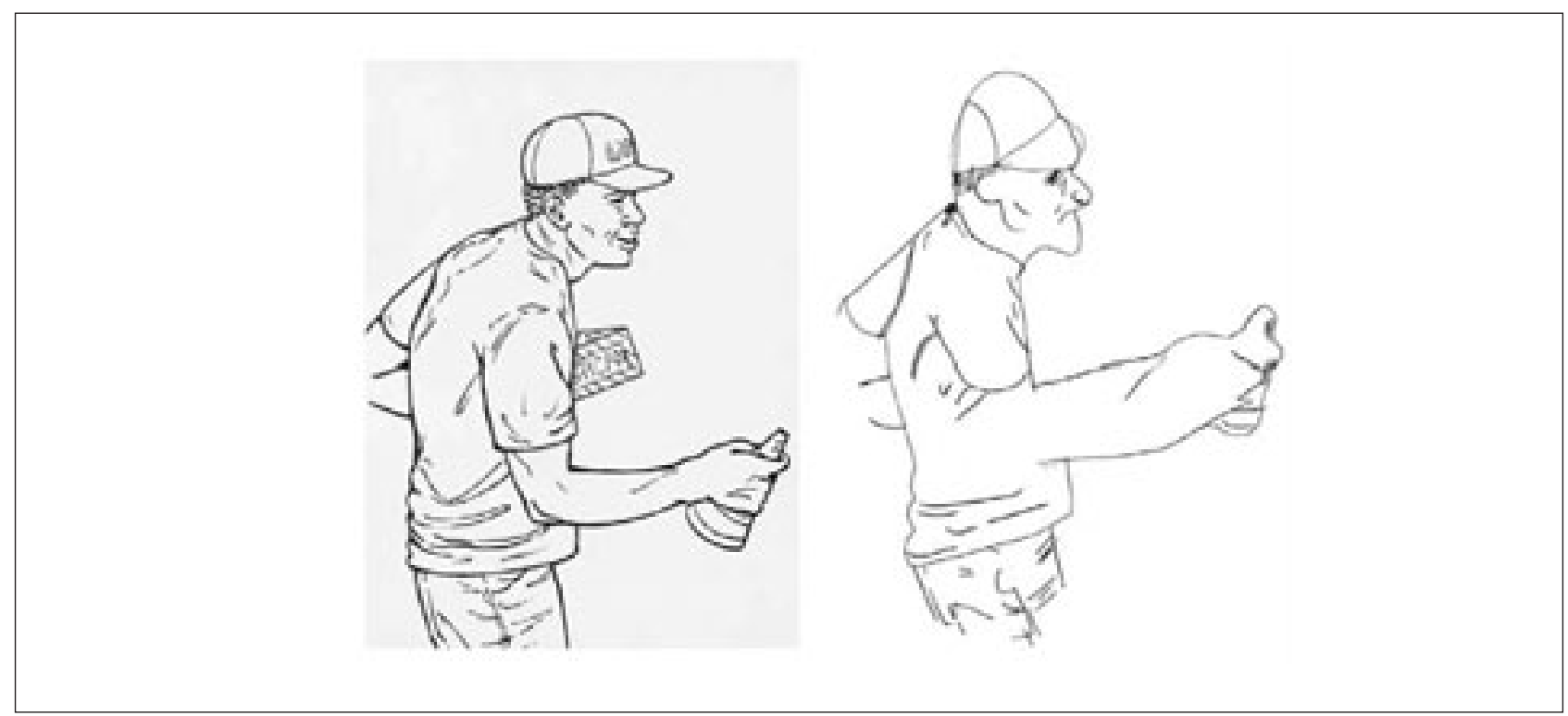

Fig. 1 - DM's copy drawing.

cues may contribute directly to his objectrecognition difficulties.

\section{CASe Report}

DM was a 19-year-old man who had suffered a closed-head injury in a car-accident around three years before testing began. He had no language deficits, no visual neglect, and full visual fields, on bedside testing. In addition to his closed head injury, he also suffered a spinal cord injury that left him paraplegic, and wheelchair-bound. He had a profound amnesia, with intact short-term or working memory (for example on Digit Span), but an inability to retain material from preceding minutes, hours and days. On assessment he was disoriented for time, although not for place and person. He was alert and had good insight into his condition.

$\mathrm{He}$ and his family reported that his visual recognition was extremely poor. $\mathrm{He}$ was unable to recognise familiar faces (for example those of his family), although he could recognise them by their voices. His family also reported a recognition deficit in daily life for visual objects other than faces. For example, while travelling by car to one testing session, he misrecognised a dog in the back of the car ahead as a 'horse', although he then realised that it should not be possible to fit a horse into a car. DM's recognition abilities were investigated clinically with a diverse range of stimulus materials, and he was found to be particularly poor (see below) at recognising linedrawings, especially for animate objects rather than artefacts, possibly relating to the greater visual similarities that exist between animate categories (Damasio, 1990; Gaffan and Heywood, 1993; Sheridan and Humphreys, 1993; Riddoch et al., 1988; though see Turnbull and Laws, 2000). In contrast to his poor recognition abilities, his copying of line drawings was good (see Figure 1), even though he often could not recognise what the original or his copy depicted. The copy shown here is representative in being fairly accurate. His performance is creditable, especially considering that DM often could not recognise what the original or the copy depicted, and his copies include many areas with excellent reproduction of detail. However, portions of the copy also appear to indicate some difficulties in segmentation and in extracting accurate 3D structure. For example, in his copy shown in Figure 1, DM did not segment the conical hat held in the person's right hand from the hand itself; he did not represent the right arm as a structure separate from the torso that it partially occludes; and he did not represent the upper arm as a structure entering the sleeve.

It is noteworthy that in everyday situations and during assessment DM appeared entirely normal in his reaching for objects and other visuo-motor activities, although this was not formally tested. For example, he was remarkably dexterous in the operation of his wheelchair - directing it around obstacles and into narrow spaces. He was also able to accurately reach for objects in near space, for example picking up a cup, or a packet of cigarettes. He was also able to successfully control a computer mouse.

\section{Clinical Assessment}

DM was assessed on subsets of the WAIS-R. He scored within the average range on Digit Span (Scaled Score 10), but was poor on Vocabulary (Scaled Score 5) and Arithmetic (Scaled Score 4), Picture Completion (Scaled Score 3) and Block Design (Scaled Score 7). 
TABLE I

DM's object recognition in various stimulus formats

\begin{tabular}{lcccl}
\hline & Animate & Artefacts & Total (\%) & Test \\
\hline Real Objects or Object Models & $13 / 17$ & $30 / 30$ & $91 \%$ & Not standardised \\
\hline Photographs & $3 / 20$ & $13 / 19$ & $68 \%$ & $\begin{array}{l}\text { Winslowe Press Black and White } \\
\text { Photographs }\end{array}$ \\
& & $14 / 19$ & $44 \%$ & Winslowe Press Colour \\
\hline Line Drawings & $5 / 13$ & $22 / 47$ & $38 \%$ & $\begin{array}{l}\text { Snodgrass and Vanderwart (1980) } \\
\text { Object Synonym Matching } \\
\text { McCarthy and Warrington (1986) } \\
\text { Graded Naming Test } \\
\text { McKenna and Warrington (1980) }\end{array}$ \\
\hline
\end{tabular}

DM performed within normal limits on the Efron Squares/Rectangles task (Efron, 1968), a test for low level impairments in form discrimination; and on the VOSP (Warrington and James, 1991) tasks of Shape Detection (19/20), Dot Centring (20/20), Dot Counting (10/10), Incomplete Letters (18/20), and Cube Counting (8/15). However, he was poor on the VOSP perceptual tasks of Object Decision (9/20), recognised only $1 / 10$ of the Warrington and Taylor Unusual Views items, and was also gravely impaired in recognising conventional views of the same items. He scored only 34/60 on the Benton et al (1983) Face Matching Test. His object recognition was also tested by using a variety of stimuli in different formats (see Table I). On these tasks DM was best in recognizing real objects (or 3D models of objects), poorer with photographs, and poorest with line drawings. For example, he recognised none of the items on the Graded Naming Test, describing a kangaroo as a 'hedgehog', a scarecrow as a 'man', a buoy as a 'boat', a thimble as a 'sieve', and made no response to the handcuffs item before this test was terminated. Also, he was poorer in recognizing animate objects than in recognizing artifacts. Both the line drawings vs. real object and the animate vs. inanimate trends are, of course, common in patients with visual agnosia (Farah, 1990; Humphreys and Riddoch, 1987; Farah and Feinberg, 1997).

In a task that we adapted from Biederman's (1987, p. 135) studies with normals, DM was shown the five fragmented and complete line drawings of a cup, wine-glass, watering-can, pair of scissors and stool. He was asked to name each on six occasions. He recognised only $11 / 30$ of the 'fragmented but geon-intact' items, even though normals are at ceiling in recognising these. However, he correctly named 29/30 of the 'complete' items. (This unusually high success rate for him, on the complete items, may be a function of our repeated presentation of these stimuli, and their high visual familiarity.)

In contrast to his typically poor performance when naming visually presented items, DM did much better when presented with verbal descriptions of objects. He scored only just outside normal limits (11/15) on the stringent Naming to Description task (Coughlan and Warrington, 1978), which asks questions such as "What is the name of the bird that flies at night and hoots?". Moreover when given a name only, and asked to provide a verbal description of the named object, DM provided accurate and concise descriptions of objects for $10 / 10$ artefacts and 8/10 animate objects.

Comment: DM shows a severe deficit in the recognition of visual objects, in the presence of relatively preserved copying ability - and might well be classified as an 'associative' visual agnosic in the traditional scheme (Farah, 1990; Grusser and Landis, 1991; McCarthy and Warrington, 1990). Moreover, while DM is clearly able to derive accurate 2D information from the visual world, there are also some preliminary grounds for suspecting that DM's recognition errors may follow from an inability to use pictorial depth cues. For example, he shows a 'standard' pattern seen in visual agnosia (Farah, 1990; Humphreys and Riddoch, 1987; Farah and Feinberg, 1997) of poorer performance in recognizing line drawings than photographs and real objects. Thus, like other cases of early visual processing impairment (Chainay and Humphreys, 2001), DM may rely, to a pathological extent, on cues that are absent in simple line-drawings, such as texture, shading, stereo and/or motion parallax cues. Also, he performs much more poorly in the recognition of fragmented line drawings that lack some of the information regarded as a central pictorial depth cue in the formation of stable object structure (Biederman, 1987). Finally, while DM's copies are accurate in many respects, he appears to show some difficulties in deriving adequate 3D structural information from line-drawings objects (see Figure 1).

To investigate these issues further, DM was given a series of experimental tasks that investigated more formally his ability to extract 2D and 3D information from line-drawings. Our general finding was that his performance was 
relatively intact on the $2 \mathrm{D}$ tasks, and by contrast was substantially impaired on the 3D tasks.

\section{D TASKS}

\section{Picture-matching across rotations in the picture- plane}

This task was performed in order to establish whether DM was able to rapidly process drawn objects and compare them across transformations in two-dimensional space. The task required matching of line drawings for identical objects that could undergo picture-plane misorientation. There is a substantial literature showing that reaction times are typically slowed with increasing misorientation when neurologically normal individuals perform such tasks (e.g. Jolicoeur, 1985). Moreover, we have also conducted several previous patient studies using such tasks (e.g. Turnbull and McCarthy, 1996a, Turnbull et al., 2002), and shown that reliably linear reaction-time performances can be produced by various patients with neurological lesions. Since only a matching response was required in the present task, identifying the object was not a logical requirement. Moreover, since any transformation was in the picture-plane only, DM was not logically required to develop or manipulate a 3D description of the object in order to successfully complete the task.

Materials and Procedure: Line drawings of 20 common objects (taken from the Snodgrass and Vanderwart (1980) corpus, see Turnbull and McCarthy, 1996a, for further details) were presented. As in Turnbull and McCarthy (1996a), the first object was presented offset by $10^{\circ}$ to the left of the screen center for $200 \mathrm{~ms}$, followed by a blank screen for $300 \mathrm{~ms}$, after which the second object appeared in the center of the screen until DM responded. The first object was always in an upright orientation, and the second object was rotated from the upright: randomly presented in one of six orientations $\left(0^{\circ}, 60^{\circ}, 120^{\circ}, 180^{\circ}, 240^{\circ}\right.$, $\left.300^{\circ}\right)$. DM was asked to judge the items as 'same' (e.g. dog-dog - note that 'same' trials always involved identical albeit rotated images) or 'different' (e.g. horse-dog) in a speeded manner. He responded with a key on the right side of the keyboard if the items were the same, and a key on the left side if the items were different. He completed three blocks of 240 trials in three different sessions.

Results: DM made only 70 errors on the 720 items of the task $(9.8 \%)$. This rate of errors is somewhat higher than that found in a small group of university-educated undergraduate control participants (mean $4.4 \%$ errors, s.d. $1.0 \%$ ), who were matched with DM for age but not education. However, it remains a creditable performance, especially given his profound difficulties in object recognition (see above). In a later session, we asked him to identify the same drawn objects as used in this experiment, in their upright orientation, and he identified only 10/20 even when given unlimited response time.

As was the case with normal subjects, DM's errors were not evenly distributed across all orientations (see Figure 2), but showed a linear increase in error rate between $0^{\circ}$ and $120^{\circ}$ [r (4) = $0.92, \mathrm{p}<0.01]$. DM also showed a significant linear increase in mean reaction time with misorientation $[\mathrm{r}(4)=0.96, \mathrm{p}<0.01]$. (As in Jolicoeur (1985), this analysis of linearity excluded the $180^{\circ}$ items, which can show faster performance than neighbouring orientations.)

Comment: While DM's reaction time performance was somewhat slower than that of normal subjects, and the slope of his RT function against orientation somewhat steeper, his performance still retains the general form seen in the sample of normal subjects - i.e. slower reaction time with increasing misorientation from the canonical orientation (Jolicoeur, 1985). This performance is remarkable, considering the profound nature of DM's agnosic deficits. His performance on this task suggests that he performs the matching of pictures using the incremental transformation strategy that is also observed in normal subjects.

An interesting feature of DM's reaction time performance was his rapid response to $180^{\circ}$ items. This finding is similar to that found by Jolicoeur (1985) in normal subjects for $180^{\circ}$ items, although the effect on reaction times for $180^{\circ}$ items was more marked in DM than was reported in Jolicoeur (1985). DM's error rate on the $180^{\circ}$ items was also lower than for the $120^{\circ}$ and $240^{\circ}$ items. Taken together, these data suggest that DM, like normal subjects, might not employ an incremental transformation strategy to match $180^{\circ}$ misoriented items (Jolicoeur, 1985).

\section{Shepard-Metzler Mental Rotation IN THE PiCTURE Plane}

The object-matching experiment described above suggests that DM employed an incremental transformation strategy in dealing with misoriented drawn objects. To test this more directly he was given the classic mental-rotation task of Shepard and Metzler (1971), which requires mirror-image discrimination rather than object matching per se (see Turnbull et al., 2002). This task involves the presentation of a pair of perspective line drawings of objects, each constructed of ten cubes (see Figure 3 ). One of the objects can be rotated relative to the other, but this only occurred within the picture plane in the present experiment (i.e only 2D differences in 


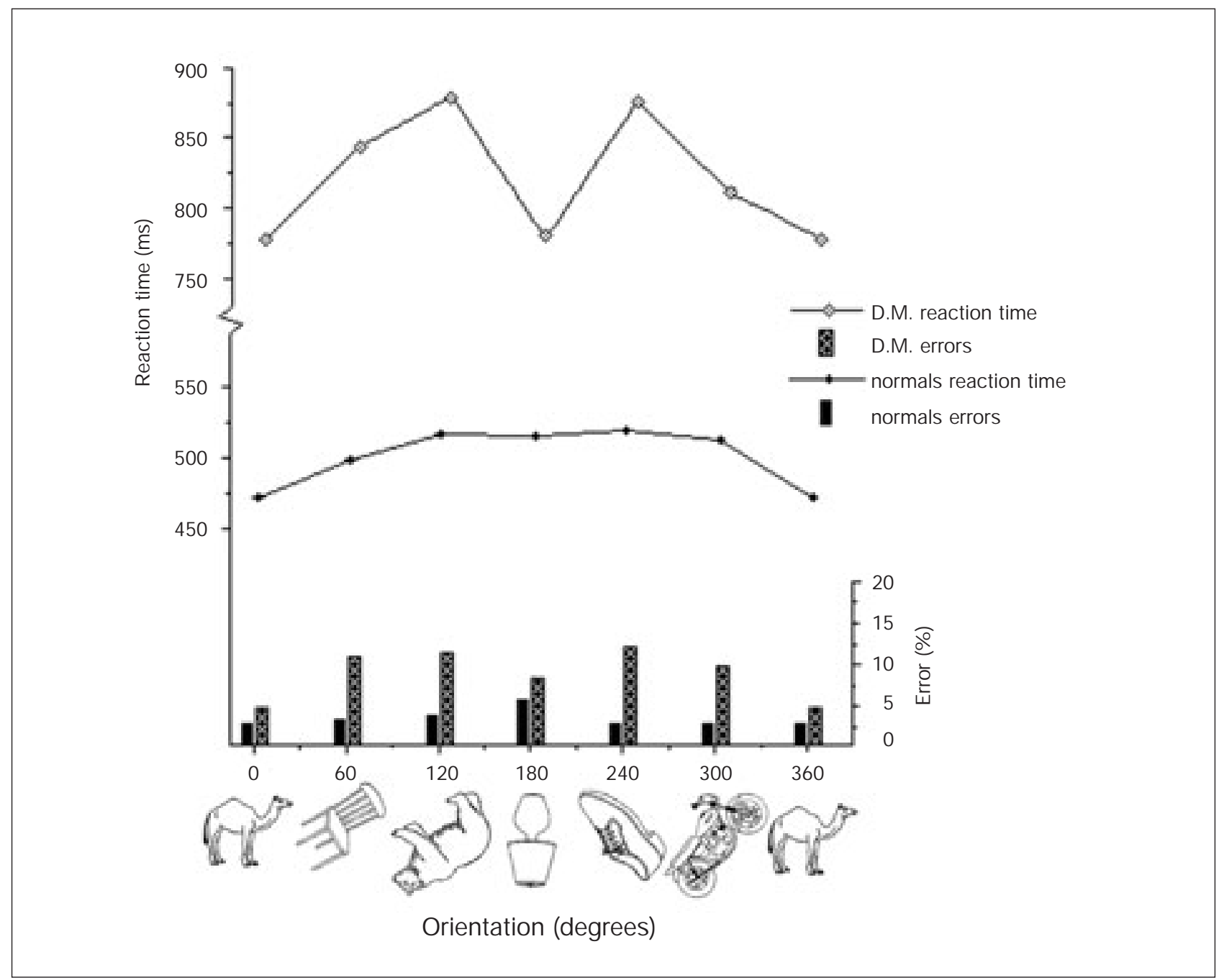

Fig. 2 - Performance in recognizing misoriented line drawing of objects.

orientation could occur). One form was either identical (but possibly rotated) with respect to the other in the same display, thus requiring a 'same' response; or was a mirror-image of that shape which could also be rotated, requiring a 'different' response.

Materials and Procedure: The figures were those used by Shepard and Metzler (1971), with a single model compared against a target presented in one of seven different orientations: $0^{\circ}, 40^{\circ}, 80^{\circ}$, $120^{\circ}, 160^{\circ}, 200^{\circ}$, and $240^{\circ}$, in either a 'standard' or 'reflected' form (as in Turnbull et al., 2002). There were 70 trials in one block, consisting of five versions of the 14 stimulus pairs (seven were 'same' and seven 'different' responses). The order of items in each block was randomised before each presentation. DM completed three blocks of the task over different sessions. The task was also performed by a control group of eight subject; four male and four female, with age ranging from 21 to 30 years.

Results: Across the three blocks, DM produced an average error rate of $10.5 \%$. This places DM's performance within normal limits compared with eight neurologically-normal control subjects, who averaged $5.7 \%$ errors (s.d. 5.5\%). The data points for stimulus pairs with orientation-differences greater than $180^{\circ}$ were combined with the mirrorimage angle below $180^{\circ}$ (as in Shepard and Metzler, 1971). Incorrect responses were excluded from reaction time analyses. The mean reaction times and errors, in relation to angular disparity, for 'same' responses (again as in Shepard and Metzler, 1971) are presented in Figure 3. DM showed a significant increase in error rate with angular disparity for orientations between $0^{\circ}$ and $120^{\circ}[\mathrm{r}(4)=0.81, \mathrm{p}<$ $0.05]$. DM's reaction time performance, as a function of orientation, likewise showed a linear increase $[\mathrm{r}(4)=0.97, \mathrm{p}<0.001]$.

Comment: In spite of his substantial object recognition deficit for line-drawings, as described above, DM appears able to perform the complex anaglyph-discrimination required by the ShepardMetzler task across transformations in the pictureplane (i.e. across changes in 2D orientation). His performance was within the normal range in terms 


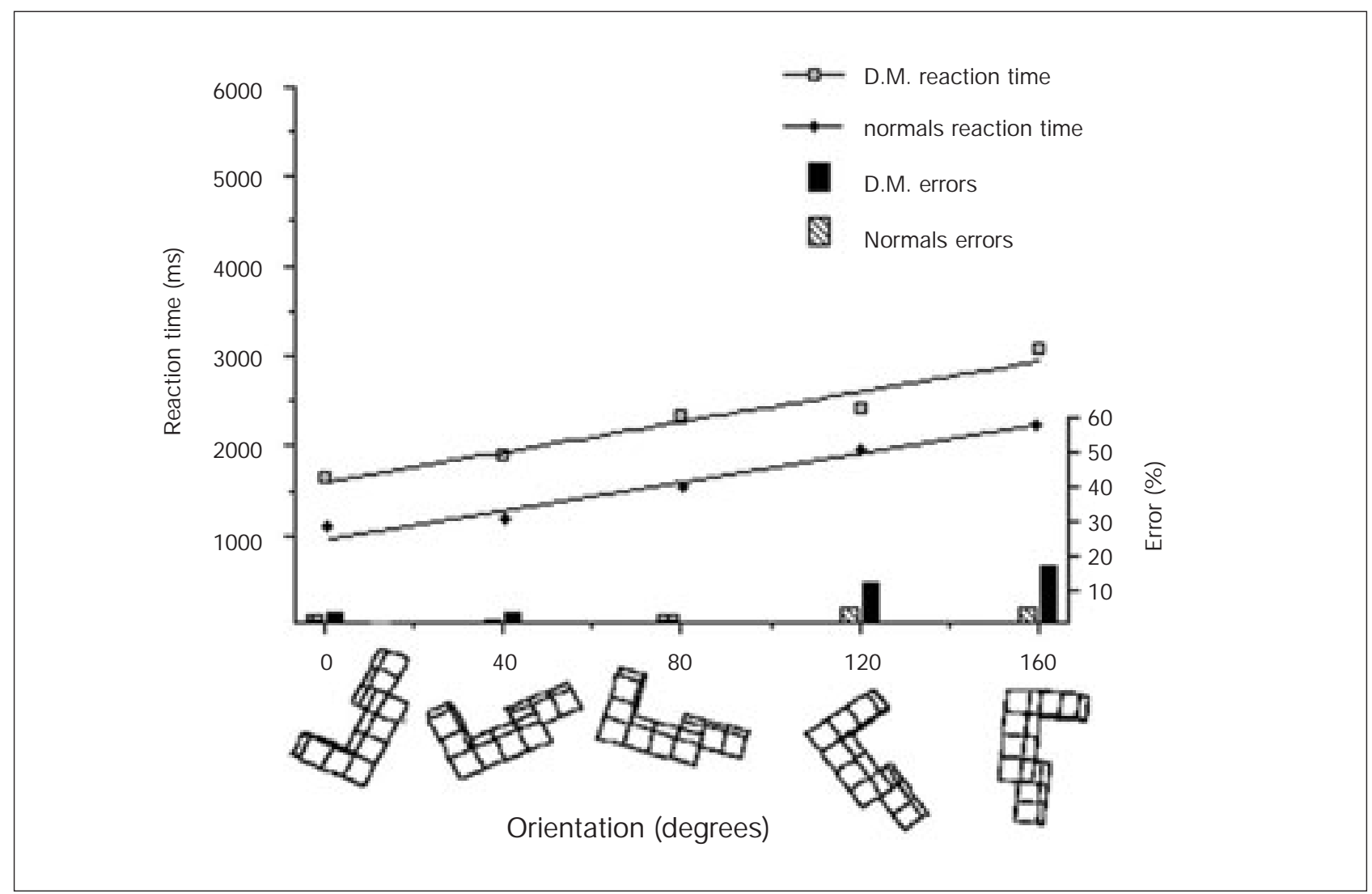

Fig. 3 - Performance in picture-plane mental rotation.

of accuracy, and showed the linear increase in reaction time with differences in orientation that is traditionally interpreted as evidence for 'mental rotation' in normal subjects (Shepard and Metzler, 1971). DM's ability to compare unfamiliar complex shapes across transformations in the picture-plane suggests that he has access to some useful description of object structure, at least at a 2D (picture-plane) level. However, we noted earlier that DM appears to have some difficulty in deriving adequate 3D structural information about objects from line-drawings. To examine this issue further, DM was given a variety of tasks assessing his ability to extract 3D from line drawings, and to cope with 3D transformations.

\section{D TASKS}

\section{Shepard-MetZler MENTAl Rotation IN DEPTH}

To further investigate the adequacy of DM's derivation of 3D structure from line drawings, he was given a depth-rotation version of the ShepardMetzler task reported above. This experiment was identical to the previous one, except that the pair of stimuli that had to be compared for the anaglyphdiscrimination on each trial could now differ in angular rotations only in the depth plane, not in the picture-plane. Thus 3D rather than 2D transformations of the objects were now involved for the first time.
Materials and Procedure: The figures were again drawn from Shepard and Metzler (1971, see Figure 4). There were again 70 trials in one block, consisting of five groups of the 14 stimulus pairs (seven requiring 'same' and seven requiring 'different' responses). The order of items in each block was randomised before presentation. DM completed three blocks of the task over different sessions. The task was also performed by the same control group of eight subjects as before. Four were male and four female, with age ranging from 21 to 30 years.

Results: The responses of normal subjects and $\mathrm{DM}$, for correct 'same' responses, are presented in Figure 4. Across the three blocks DM's accuracy performance was not significantly different from chance, with an average error rate of $46.7 \%\left[\chi^{2}\right.$ $(209)=112, p>0.05]$. This effect was stable over the three successive blocks $(25 / 70,38 / 70$ and 35/70 errors). In contrast, normal subjects made an average of $8.0 \%$ errors (s.d. $6.0 \%$ ).

As might be expected, given that the DM's accuracy on the task was close to chance, his reaction time performance as a function of orientation no longer showed a significant linear increase with angular disparity $[\mathrm{r}(4)=0.44, \mathrm{p}>0.05]$.

Comment: DM's performance on this 3D mentalrotation task was at chance, which contrasts with his good performance for the picture-plane mental 


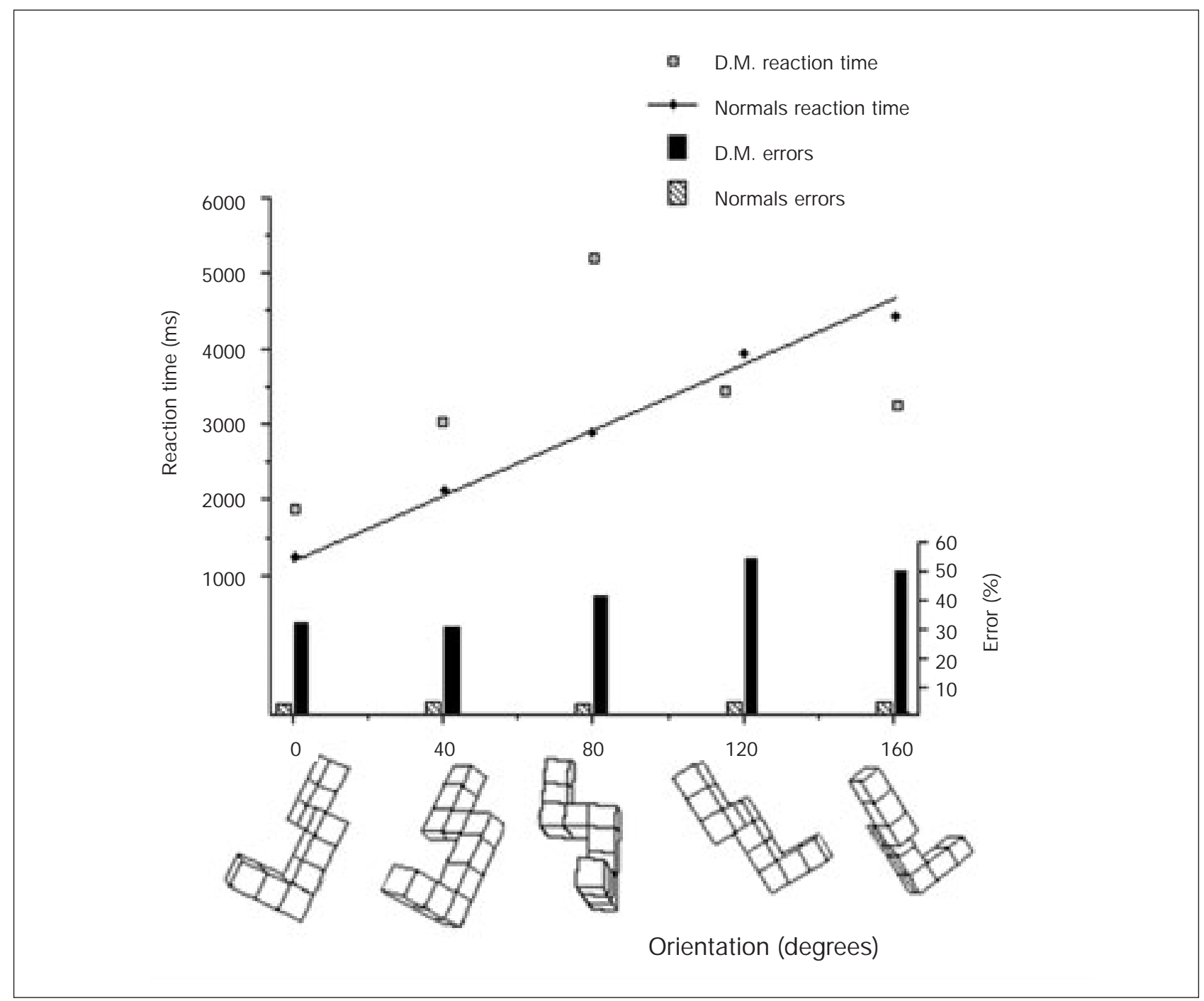

Fig. 4 - Performance in depth mental rotation.

rotation task in the previous experiment (compare Figures 2 and 3, against Figure 4), in which DM had shown an error rate within the normal range (10.5\%). A comparison between DM's error scores on the depth versus picture-plane mental rotation tasks confirmed a significant difference in performance $(\mathrm{t}=3.7, \mathrm{p}<0.05)$.

The striking difference in DM's performance between the two mental rotation tasks (2D versus 3D) may have some bearing on findings about mental rotation in normal subjects. The classic cognitive psychology literature on normal performance has reported that the accuracy and speed of performance might be equivalent for picture-plane and depth-plane mental rotation tasks (R. Shepard and J. Metzler, 1971; S. Shepard and D. Metzler, 1988; but see Jolicoeur et al., 1985; Bauer and Jolicoeur, 1993). However, the dramatic difference in performance on the two versions of the task in DM suggests that they can involve different processes, which may be selectively disrupted.

DM's inability to perform the 3D mental-rotation task could directly reflect an inability to derive appropriate 3D structural interpretations of the forms shown, consistent with some of the clinical evidence we presented earlier. Alternatively (or in association) it might also involve a deficit in implementing 3D transformations of extracted forms. To investigate this further, a new task was devised in which DM's ability to derive 3D interpretations of shape from line drawings was tested, but now without requiring any mental rotation, nor any comparison across transformed images.

\section{DEPTH JUDGMENTS WITHIN LINE-DRAWINGS OF SHEPARD-METZLER FORMS}

In this task DM's ability to derive 3D information from line-drawings was assessed, by asking him to judge which of two dots placed on the surface of a form depicted in a line-drawing was 'closer' to him. The task employed the same type of drawn Shepard-Metzler form that DM had previously seen in the 'mental rotation' task (see Figure 4). This new task was devised in order to 


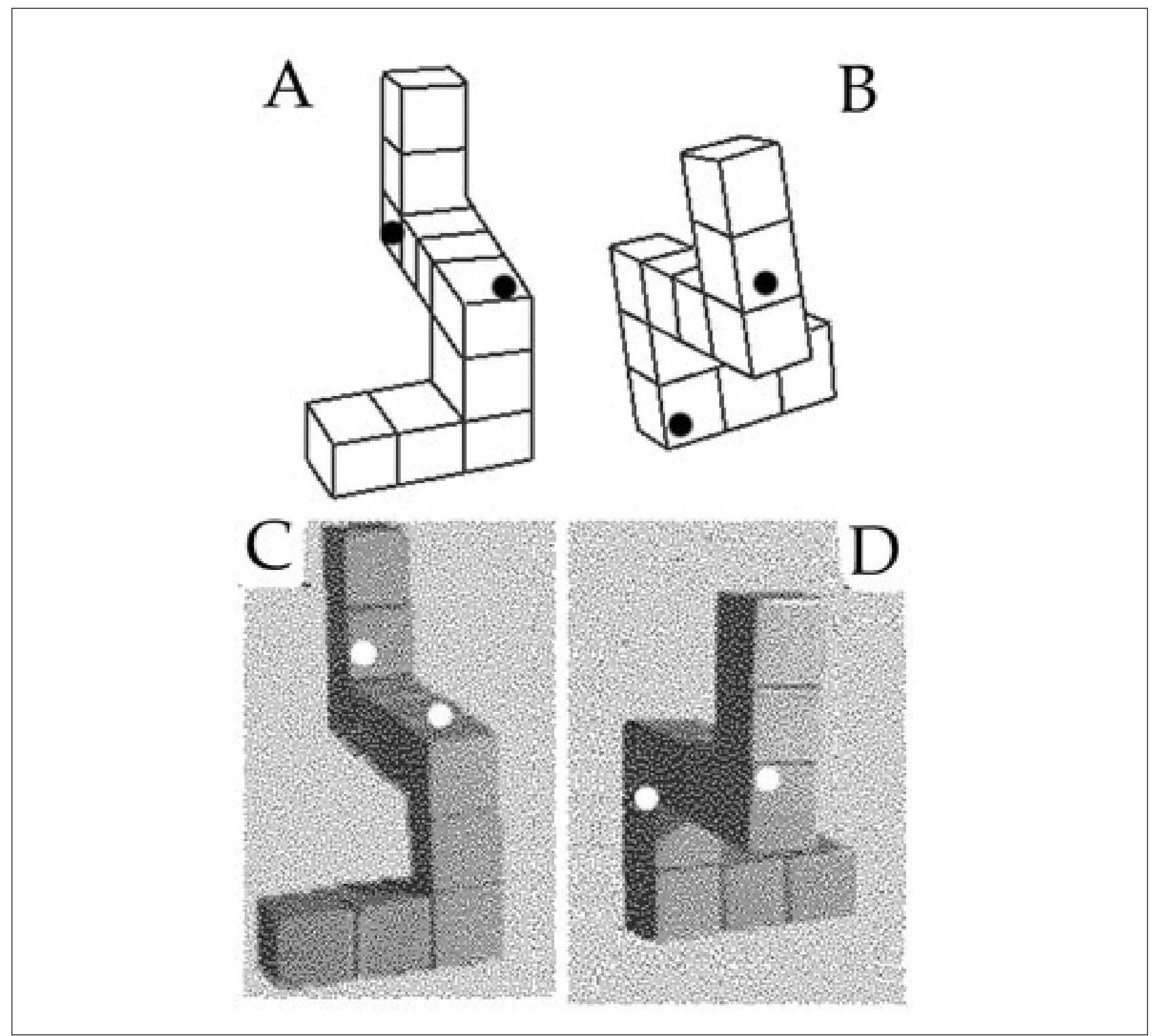

Fig. 5 - Stimuli for dot-depth judgement;

establish whether DM's failure on the 3D 'mental rotation' task was due solely to an inability to perform 3D transformations, or might involve a deficit in extracting the 3D structure of the depicted shape.

Materials: Six examples of Shepard and Metzler (1971) figures were used. Each form now had two dots placed on the surface, such that one dot would clearly be considered 'closer' to the viewer when the line drawing is given an appropriate 3D interpretation (see Figure 5A and 5B). The placement of the dots in terms of their relative elevation was balanced so that for some forms (such as Figure 5A) elevation-inplane was a correct predictor of the relative depth represented by the two dots: i.e. the lower dot would be 'closer' to the observer in the three-dimensional form represented by the drawing. In the other forms (such as Figure 5B) the dot lower on the screen would be 'further' from the subject following 3D interpretation. We stress the factor of elevation, because this can relate to depth as shown not only in Gibson's classic work on pictorial depth-cues (Gibson, 1966) but also by several recent findings. For example, Gardner and Mon-Williams (2001) have shown that elevation cues provided by gaze angle can influence depth processing in visuallyguided action. Similarly, Marotta and Goodale (1998) have suggested that height in the visual field can be used to influence aiming, reaching and grasping movements under monocular conditions.

We employed six Shepard-Metzler shapes in the task. Three variations in dot position were used for each form, which altered the vertical and horizontal distance between the dots. In a 'Large vertical separation' version (e.g. Figure 5B), the vertical distance between the dots greatly exceeded the horizontal distance (across all stimuli the average ratio was $1.9: 1$ ). The distances were approximately 
equal in a 'Balanced vertical separation' version (average ratio $0.9: 1$ ). In a 'Small vertical separation' version (e.g. Figure 5A) the vertical distance was smaller than the horizontal distance (average ratio $0.5: 1$ ). These differences in vertical separation were included to establish whether there was any gradient of accuracy associated with task difficulty.

In sum, here we employed 18 stimuli, consisting of six Shepard-Metzler forms, each with three possible differences in vertical separation between the dots. A block of 90 items was devised, consisting of 5 repetitions of each of the 18 items. As a control task, to tap DM's ability to derive two dimensional information from the drawings, DM was asked to judge which of the two dots was 'higher' in each image. It was anticipated that DM's 'elevation' judgment would be good, given that he seems able to extract 2D information with a reasonable degree of accuracy. However, we predicted that his 3D 'depth' judgments would be poor, since they require information about pictorial depth to be extracted.

Procedure: In the 3D task, DM was asked to push a key, identified on the right of the keyboard, if the dot on the right would be 'closer' to him in a three dimensional version of the form, and a key on the left of the keyboard if the dot on that side was 'closer'. In the 2D control task, DM was asked just to ignore the Shepard-Metzler forms altogether and simply concentrate on the height of the dots, pressing the right-sided key if the dot on the right was higher on the screen, and the left sided key if the left dot was higher. DM was given four blocks, each with 90 trials. The $3 \mathrm{D}$ or $2 \mathrm{D}$ tasks were presented in a counter-balanced (ABBA) order, beginning with the $3 \mathrm{D}$ task. DM was given a short break between blocks.

Results: For the 3D depth task, DM made $48 / 180$ errors $(26.6 \%)$. Almost all of these errors were on those items where elevation did not correctly predict depth. His error rate ranged from $0 \%$ to $7 \%$ for items where the vertical separation predicted depth (mean $2.2 \%$ ), and from $33 \%$ to $87 \%$ for items where the vertical location did not predict depth (mean 51.1\%). There was no significant difference in DM's performance as a function of the three classes of ratio between horizontal versus vertical distance between the dots. Reaction time performance did not correlate with either the ( signed) vertical $[\mathrm{r}(17)=0.09, \mathrm{p}>0.05]$ or horizontal distance between the dots $[\mathrm{r}(17)=0.10$, $\mathrm{p}>0.05]$.

On the 2D control task, DM made only $1 / 180$ errors $(0.56 \%)$. There was a significant relationship between vertical separation and reaction time performance on this task $[\mathrm{r}(17)=0.60, \mathrm{p}>0.05]$.

Comment: DM's performance on the 3D task appears strongly related to the variable of $2 \mathrm{D}$ elevation differences between the two dots. DM made accurate judgments for the forms for which elevation correctly predicted depth (2\% errors). For the items in which relative elevation did not predict the relative depth of parts of the form, he performed much more poorly (51\% errors). Although horizontal distance between the dots also varied across the stimuli, this did not predict DM's performance. In contrast, DM could accurately discriminate the relative two-dimensional position of the dots $(0.6 \%$ errors $)$.

Taken together, these findings suggest some deficit in extracting correct 3D interpretations of line-drawings. His failure in the earlier 3D mental rotation task, reported above, cannot necessarily be attributed to a deficit in mental rotation in depth per se, given that it might also or instead reflect a deficit in the more elementary ability of deriving appropriate depth information from 2D information.

\section{DEPTH JUDGMENTS FOR PARTS OF SHADED SHEPARD-METZLER FORMS}

Our general clinical assessment of DM had suggested that his object recognition performance might be better when viewing real objects, or their photographs, than for simple line-drawings with no shading. We next examined whether he would perform better at judging the relative depth of two dots placed on surfaces of a Shepard-Metzler blockform if these had additional depth cues (with shading in particular). The new task was as in the previous experiment, except that the stimuli were now digital photographs (see Figures 6C and 6D), converted to bit-map graphics.

Procedure: The procedure was identical to the previous experiment, apart from the change in stimuli. DM again performed four blocks of 90 trials each, two for the 3D judgements and two for the $2 \mathrm{D}$ control task.

Results: For the 3D depth task, DM made 55/180 errors $(30.5 \%)$. All of these errors were on those items where elevation did not correctly predict depth. His error rate ranged from $37 \%$ to $87 \%$ for items where the vertical separation did not predict depth (mean 61.1\%). As with the line drawing stimuli in the previous experiment, there was no significant difference in DM's performance as a function of the three classes of ratio between horizontal and vertical distance between the dots. Reaction time performance did not correlate with either vertical $[\mathrm{r}(17)=0.4, \mathrm{p}>0.05]$ or horizontal distance between the dots [ $\mathrm{r}(17)=0.13, \mathrm{p}>0.05]$.

In the control 2D task, DM performed perfectly $(0 / 180)$ errors. As in the previous task, there was a significant relationship between elevation and 


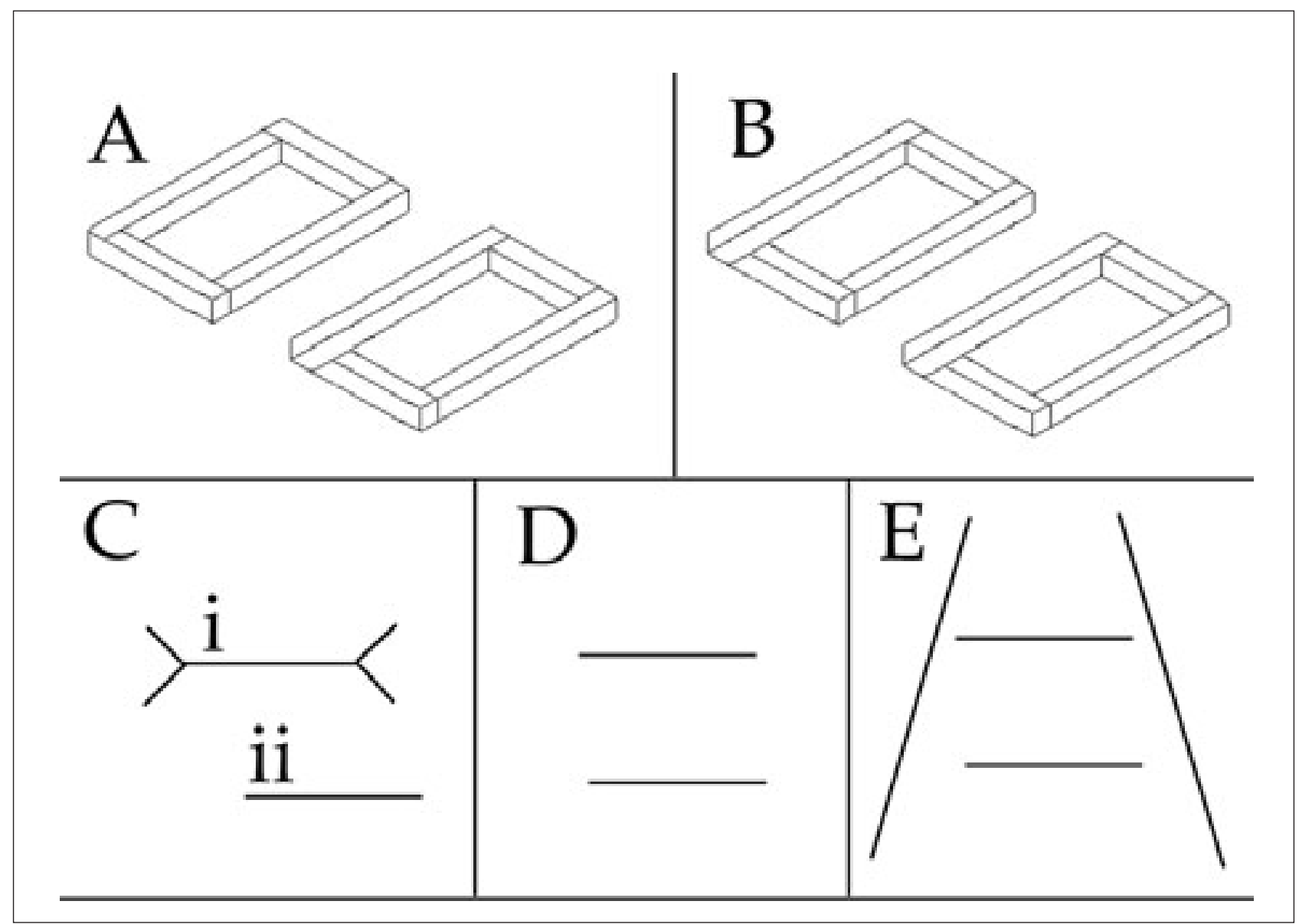

Fig. 6 - Stimuli for impossible object and visual illusion tasks.

reaction time performance on the task $[\mathrm{r}(17)=$ $0.62, \mathrm{p}<0.05]$.

Comment: These results serve to replicate those for line-drawings in the previous experiment. DM performed well on items where the relative elevation of the dots was an accurate predictor of 3D form, but was at chance, or worse, for the items in which relative elevation did not predict the relative depth of parts of the form. However, he could accurately discriminate the relative $2 \mathrm{D}$ position of the dots. The fact that DM's performance with the 'shaded' stimuli did not improve over that with simple line drawings suggests that this did not provide a sufficient cue to depth for him in this task.

\section{DisCRIMINATING 'POSSIBLE' VERSUS 'IMPOSSIBLE' OBJECTS FROM LINE-DRAWINGS}

The ability to discriminate structurally 'possible' from 'impossible' objects (Penrose and Penrose, 1958) has been used as one index of normal observers seemingly effortless ability to derive 3D structure from line drawings (e.g. see Gregory, 1970; Young and Deregowski, 1981). A test of this has also been applied to at least one neuropsychological case of visual agnosia, patient MS of Ratcliffe and Newcombe (1982), who was able to copy line drawings of objects accurately that he could not recognise. He was unable to discriminate possible from impossible objects, and apparently also took as long to copy possible as impossible objects (Farah, 1990, p.63), unlike normals who are typically faster to copy linedrawings of objects that are 'possible' in 3D.

Given DM's apparent deficit in processing the 3D structure of objects depicted in line-drawings, we anticipated that he would also be impaired at judging whether they depicted possible or impossible objects. As a control to check that he was nevertheless able to resolve the fine 2D details that distinguished possible and impossible versions, in a separate task we asked him to judge whether two versions were the same or different, regardless of their possible or impossible nature.

\section{Stimuli and Procedure}

The stimuli were the 'diamond' and 'rectangle' drawings taken from the set of 'possible' and 'impossible' objects generated by Young and Deregowski (1981, see Figure 6A). These stimuli were presented in pairs, with each pair on one sheet of paper, for DM to view for as long as he wished. 
In the 3D task (see Figure 6A), one 'possible' and one 'impossible' drawing was presented to DM as a pair. He was told that he would see two drawings, "one of which is a 'good' drawing, while one is a 'bad' drawing that doesn't make sense if you look closely" (c.f. Young and Deregowski, 1981). In a forced-choice paradigm DM was asked to select the 'bad' or 'impossible' drawing by pointing at it. The position of the correct item was pseudo-randomly varied across blocks of ten trials, such that the correct response item was not biased towards the left or right side.

In the 2D control task (Figure 6B), DM was again presented with pairs of drawings, drawn from the same possible and impossible sets, but now paired such that both could be possible, both impossible, or one possible and the other impossible (the latter applied to $50 \%$ of trials). The task was now to indicate whether the two drawings on any trial were the 'same' or 'different', regardless of whether they were possible or impossible.

Results: On the 3D possible-impossible discrimination task DM was correct on $5 / 10$ of the Diamond items, and $6 / 10$ of the Rectangle items, and thus no better than chance overall $(11 / 20)$. On the same-different discrimination items (Task B) DM was correct on 10/10 of the Diamond items, and $10 / 10$ of the Rectangle items. This difference in performance between the $3 \mathrm{D}$ and the $2 \mathrm{D}$ tasks was significant $\left(\chi^{2}=11.6, \mathrm{p}<0.001\right)$.

Comment: DM had great difficulty in deciding on the 3D plausibility of the 'impossible' objects presented as drawings. This is similar to the performance of the agnosic patient reported by Ratcliff and Newcombe (1982) who also had good copying skills. However, DM was able to see the 2D features of the line-drawings clearly enough to discriminate between same and different items (an important control that was not implemented by Ratcliff and Newcombe). A plausible interpretation of these data is that the same-different task can be completed without a requirement to extract an appropriate 3D description of the drawn object, but the possible-impossible task requires the extraction of $3 \mathrm{D}$ structure.

\section{Insensitivity to MÜlleR-Lyer AND Ponzo VISUAL ILLUSIONS}

Normal observers show various illusions in which they fail to accurately judge the twodimensional extent of lines. The best known examples are the Muller-Lyer and Ponzo illusions (Goldstein, 1996; Gregory, 1966; Sekuler and Blake, 1990, see Figures 6C and 6E). Although the exact psychological and neural basis of these illusions remains controversial, on one influential account they may result at least in part from pictorial depth cues leading to the misapplication of size-constancy mechanisms (Gregory, 1966). However, while there is some experimental support for this hypothesis from studies of normal perception, it remains contested (e.g. De Lucia and Hochberg, 1991; Hochberg, 1987). We reasoned that if the Muller-Lyer and Ponzo illusions are indeed at least in part due to pictorial depth-cues, and if patient DM fails to utilise such depth-cues in the normal manner, then he might fail to show these illusions to the normal extent. We note also that many recent investigators have suggested that the conscious perception of visual illusions may depend on ventral stream mechanisms (e.g. Aglioti et al., 1995) that are classically damaged in object agnosics, although this perspective is not without its critics (e.g. Franz et al. 2000; Jackson and Shaw, 2000; for review see Carey, 2001).

DM was now required to perform line-length judgments in situations that can induce the MullerLyer or Ponzo illusions. Note that according to the hypothesis presented above, we derived the paradoxical prediction that in these tasks DM would actually be more accurate than normal subjects!

Stimuli and Procedure: This experiment was run using 'Eye Lines' software (Beagley, 1990), which offers one standard experimental paradigm for testing the Muller-Lyer (Figure 6C) and Ponzo illusions (Figure 6E). The subject actively manipulated the length of a plain line (ii), by mouse control, to match the length of a target line (i), under 'illusion' or 'control' conditions. In the Muller-Lyer experiment 'illusion' condition, the target was the classic horizontal ' $\mathrm{Y}$ '-junction Muller-Lyer form (Figure 6C). Below this target, and offset relative to it, was a line (with no Yjunctions) whose length was under DM's control through mouse-manipulation. DM was required to match the length of the two lines. In the control condition (Figure 6D) the target was a plain line, of the same length as in the 'illusion' condition, and again the length of a plain second line was controlled by DM, who was asked to match the length of the two lines.

In the Ponzo version of the experiment (see Figure 6E) the 'illusion' condition involved the same two horizontal lines now placed between two vertically angled lines providing the standard Ponzo illusion of depth - such that the target line is usually experienced as longer than its veridical length. Again, the control condition consisted of the two lines alone (Figure 6D). The veridical length of the control line was $10.6 \mathrm{~cm}$, viewed at a distance of approximately $40 \mathrm{~cm}$.

The Muller-Lyer task was administered in one session. It involved 15 'illusion' and 15 'control' trials, presented in random sequence - again such that with any illusion the target line should be experienced as longer than its veridical length. The Ponzo task was given in a separate session, also in a 
random sequence of 15 'illusion' and 15 'control' trials. Four neurologically-normal participants, matched for age, also completed the tasks.

Results: Muller-Lyer illusion: DM's mean chosen length under the 'illusion' condition was $10.8 \mathrm{~cm}$ (s.d. $0.9 \mathrm{~cm})$. For the control condition his chosen length was also a mean of $10.8 \mathrm{~cm}$ (s.d. $0.9 \mathrm{~cm}$ ); thus, DM did not exhibit any illusion. For the neurologically-normal control participants, the mean length under the illusion conditions was 12.2 $\mathrm{cm}$ (s.d. $0.6 \mathrm{~cm}$ ), which was significantly different from DM's illusion condition (Mann-Whitney U' = 206, p $<0.001)$. The neurologically-normal participants gave a mean length of $10.8 \mathrm{~cm}$ (s.d. 0.3 $\mathrm{cm}$ ) in the no-illusion condition, which was significantly different from their illusion performance $\left(\mathrm{U}^{\prime}=152, \mathrm{p}>0.05\right)$. Every control subject showed the illusion.

Ponzo illusion: DM's mean chosen length under the 'illusion' condition was $10.9 \mathrm{~cm}$ (s.d. $0.6 \mathrm{~cm}$ ). For the control condition his chosen length was also a mean of $10.9 \mathrm{~cm}$ (s.d. $0.5 \mathrm{~cm}$ ); thus he showed no Ponzo illusion. For the neurologically-normal participants, the mean under illusion conditions was $11.7 \mathrm{~cm}$ (s.d. $0.3 \mathrm{~cm}$ ), which was significantly different from DM's illusion condition (U' = 199, $\mathrm{p}<0.001)$. The neurologically-normal participants showed a control condition performance of $10.8 \mathrm{~cm}$ (s.d. $0.3 \mathrm{~cm}$ ), which was significantly different from their illusion performance $\left(U^{\prime}=116, p>0.05\right)$. Again, every control subject showed the illusion.

Comment: While neurologically-normal participants showed a Muller-Lyer and a Ponzo illusion, DM's performance on the 'illusion' condition did not differ from the control condition. Thus, he was exceptional in not showing either illusion, making his performance more accurate than that of normal control subjects on the 2D length judgements.

One intepretation of this pathologically good performance would be consistent with Gregory's (1966) intepretation of the Muller-Lyer and Ponzo illusions in terms of pictorial depth cues leading to misapplication of size constancy. We have shown earlier that DM has deficits in 3D interpretation of line-drawings which contain only pictorial cues to depth. A deficit in use of pictorial depth cues by DM might then eliminate the Muller-Lyer and Ponzo phenomena on Gregory's (1966) account of these illusions, consistent with our findings. Another possible way to formulate the finding may be that patient DM groups or segments the components of Muller-Lyer and Ponzo stimuli differently to normal observers. This could either provide an alternative account to the pictorial-depth-cue hypothesis, or merely a different way of stating the Gregory interpretation. Further research with agnosic patients might be able to distinguish these possibilities. For now, the present results show one way in which DM's vision is pathologically supranormal; his 2D line-length judgements are not subject to illusions that lead to powerful distortions of perception in normals.

\section{GENERAL Discussion}

DM, a patient with visual agnosia, is capable of successfully performing a variety of tasks involving the representation and manipulation of pictorial stimuli that require only two-dimensional coding. Thus, he is accurate and shows an apparently normal strategy in matching picture-plane misoriented object stimuli, and when performing picture-plane image rotations. Also, his copying of line drawings is relatively good - given that copying need not rely on the use of pictorial depth cues. However, he performs poorly on a variety of tasks that require him to derive three-dimensional representations from line drawing, such as discriminating possible from 'impossible' objects, performing mental rotation in the depth-plane for 2D line-drawings of $3 \mathrm{D}$ objects, and judging the depth depicted in line drawings and shaded photographs. These findings strongly suggest that he has a primary deficit in his ability to extract pictorial depth cues. He appears to ignore cues to perspective, such as junction information that signals occlusion and interposition. Moreover, he does not show the classic Muller-Lyer and Ponzoillusions, possibly because of his deficits in pictorial depth-cues (and/or because of pathological segmentation of the inducing stimuli). There is some evidence that DM might rely on the simple cue of elevation when forced to make depth judgements where the only cues to depth are pictorial.

Our findings of deficits in extraction and use of 3D object structure from pictorial depth cues begs the question of whether DM's pictorial-depth deficits form the basis for his difficulties in recognising visually presented objects. There is some preliminary evidence to support this claim. Notably, DM is severely impaired in his recognition of line drawings of objects, but is far less impaired in recognizing real objects. One explanation of this effect might be that the primary difference between line drawings and real objects is the quality of surface information that they provide - with real objects providing excellent surface cues, and line drawings being devoid of such information. Also, real objects can be parsed in depth by the use of stereopsis, as well as visuo-motor (i.e. cephaloocular) exploration, yielding motion parallax and changing patterns of occlusion. One interpretation of the present findings would be that DM has lost a key subset of the edge-based recognition skills that most humans use for rapid object identification 
(Biederman, 1987). On this account, DM would be left only with 'surface-based' cues, which would be adequate for the recognition of many real objects, but would severely impair his recognition ability when the stimuli were line drawings of objects.

These data may also be of interest in the context of a recent debate on the necessity of three dimensional information for object recognition. There have, of course, been long-standing attempts to model object recognition with the requirement that early vision derive a full three dimensional (structural) description of the object before recognition (e.g. Marr, 1982; Biederman, 1987). However, a number of more recent attempts at modelling recognition have attempted to demonstrate that object recognition can be achieved on the basis of two dimensional information alone (e.g. Bulthoff et al., 1995; Tarr and Bulthoff, 1998). In this respect, then, DM might conceivably represent a test case of the extent to which humans can recognise objects from line-drawings without pictorial depth information. On this interpretation, the answer would be that DM's recogniton performance appears to be greatly impaired. It remains an open question as to whether DM's visual agnosia is a secondary consequence of this primary depth-perception deficit. However, it is notable that, like many visual agnosics, DM's recognition is enhanced when objects are presented with richer depth cues - in photographs and with real objects.

It has long been recognised that $2 \mathrm{D}$ information is the more primitive class of cue available from pictorial input, and that depth information can be constructed from pictorial cues (amongst other types of depth cue) and may require construction on the basis of a range of secondary cues (Marr, 1982). Does DM's profile simply reflect 'task difficulty', rather than a selective perceptual impairment? We would contend that his disorder should be considered alongside those of other cases whose deficit appears by contrast to be more significant for 2D cues - patients who are able to identify line drawings and complex forms - but who are quite unable to judge their location and orientation in space. For example, patients who cannot discriminate between a picture and its mirror-image (Gold et al., 1995; McCloskey et al., 1995; McCloskey and Rapp, 2000, Turnbull and McCarthy, 1996), and patients who do not show stability in orientation either for the entire pictureplane (Solms et al., 1988), or for objects within it (Solms et al., 1998; Turnbull et al., 1995; 1997). DM's impairment in extracting 3D cues from 2D stimuli may reflect yet another dissociation within spatial processing systems. Unlike these other cases, in which selective aspects of $2 \mathrm{D}$ processing are impaired, DM shows a high level of competence in dealing with 2D cues, but is significantly impaired in his ability to go beyond the second dimension and into the third based on pictorial cues.

We also wish to contrast DM's severe problems in processing pictorial cues to depth with the remarkable sparing of his ability to use 3D cues for action that is apparent in his daily life. With the exception of De Renzi's pioneering work, most previous investigations of depth perception in patients with cortical visual disorders have focussed almost exclusively on 3D depth cues in the context of visually-guided action. In such cases the role of the dorsal visual system has been emphasised (see Carey et al., 1998; Dijkerman et al. 1999; Servos and Goodale, 1998). While DM's ability to use depth for the purposes of action was never formally assessed by us, our impression was that he could use three dimensional depth cues with great accuracy for the purposes of action. For example, he was able to manipulate his wheel-chair without apparent error through narrow spaces, judging the distance to ramps, corners and the edge of pavements. He could reach accurately for everyday objects at a range of distances, even accurately performing precise tasks such as lighting a cigarette, and at no stage showed errors of visually-guided action that have been traditionally classified as optic ataxia. Nevertheless, more formal testing of his abilities in these domains would be useful.

DM's apparently good performance of such depth-related visuo-motor skills contrasts with his very poor performance when he was required to extract depth information from pictures. This potential dissociation between depth processing for pictorial perception versus depth perception for action agrees with many other lines of evidence that depth information is not a unitary information resource, processed by a single 'module'. Rather, different aspects of depth processing appear to be represented separately, so that these can be selectively impaired. We might speculate that cues such as motion parallax, optic flow, optic convergence and possibly binocular disparity might be optimally employed by the (action-oriented) dorsal visual system, while linear pictorial depth cues (T-junctions, occlusion-interposition, and perspective cues related to the vanishing point) are employed by the (recognition-oriented) ventral system. Additional flexibility is suggested by the fact that, under sub-optimal conditions, sensorimotor systems can 'make do' with monocular cues (e.g. Gardner and Mon-Williams, 2001; Marotta and Goodale, 1998), and may use two-dimensional pictorial cues for obstacle avoidance (Haffenden and Goodale, 2001).

The fact that DM appeared unable to extract pictorial depth, and also was not affected by common visual illusions, is of some interest with regard the recent debate on the role of $2 \mathrm{D}$ vs $3 \mathrm{D}$ information in visual illusions of extent. The striking Titchener Circles findings of Aglioti et al (1995) suggested that such visual illusions might arise only for consciously mediated (ventral?) estimates of size, but not for (dorsally-mediated?) 
visually guided reaching (see Carey, 2001 for review of this controversial topic). However, as Carey points out (p.112), there are some tasks in which visually guided action appears to be affected by purely two dimensional information - a point recently supported by the findings of Kwok and Braddick (2003) on reaching to Titchener Circles.

To conclude, across a number of tasks we have shown that the agnosic patient DM presents with a deficit in his ability to extract pictorial depth information from 2D images, often relying on height in plane instead - a simple monocular cue to depth. In contrast, his ability to extract accurate 2D information from the same images, and even to manipulate such images in two dimensional rotation tasks, remains basically intact. He therefore represents a further subtype of the many selective disorders of space exploration and cognition that were so clearly outlined in De Renzi's pioneering monograph.

Acknowledgements: Our thanks to DM for taking the time to complete the various tasks reported in this paper so cheerfully, and to David Carey for encouragement and patience. Both JD and OT are supported (separately) by the Wellcome Trust, and JD holds a Royal SocietyWolfson Research Merit Award.

\section{REFERENCES}

Aglioti S, Desouza JFX and Goodale MA. Size-contrast illusions deceive the eye but not the hand. Current Biology, 5: 679-685, 1995.

BAUER B and Jolicoeur P. Stimulus dimensionality effects in mental rotation. Canadian Society for Brain, Behaviour and Cognitive Science: 53-54,1993.

BEAGLEY WK. Eye-lines: A tool for studying visual perception of size and angle. Behaviour Research Methods, Instruments and Computers, 23: 183-186,1990.

BIEDERMAN I. Recognition-by-components: A theory of human image understanding. Psychological Review, 4: 115-147, 1987.

Bulthoff HH, Edelman SY and TARR MJ. How are threedimensional objects represented in the brain? Cerebral Cortex, 3: $247-260,1995$

CAREY DP. Do action systems resist visual illusions? Trends in Cognitive Sciences, 5: 109-113, 2001.

Carey DP, Dijkerman HC and MiLner AD. Perception and action in depth. Consciousness and Cognition, 7: 438-453, 1998.

Chainay $\mathrm{H}$ and Humphreys GW. The real-object advantage in agnosia: Evidence for a role of surface and depth information in object recognition. Cognitive Neuropsychology, 18: 175$191,2001$.

Cowan TM. The theory of braids and the analysis of impossible figures. Journal of Mathematical Psychology, 11: 190-212, 1974.

CoweY A. Why are there so many visual areas? In FO Schmidt, FG Warden, G Adelman and SG Dennis (Eds), The Organisation of the Cerebral Cortex. Cambridge, MA: MIT Press, 1981, pp. 395-413.

DAMASIO AR. Category-related recognition deficits as a clue to the neural status of knowledge. Trends in Neuroscience, 13: 9598, 1990.

Delucia PR and Hochberg J. Geometrical illusions in solid objects under ordinary viewing conditions. Perception and Psychophysics, 50: 547-554, 1991.

De Renzi E. Disorders of Space Exploration and Cognition. Chichester: Wiley, 1982.

De Renzi E and Di Pellegrino G. Prosopagnosia and alexia without object agnosia. Cortex, 34: 41-50, 1998

De Renzi E and Faglioni P. The relationship between visuospatial impairment and constructional apraxia. Cortex, 3: 327342,1967

Dijkerman HC, Milner AD and Carey DP. The perception and prehension of objects oriented in the depth plane: 1 . Effects of visual form agnosia. Experimental Brain Research, 112: 442451, 1996.

Dijkerman HC, Milner AD and CARey DP. Motion parallax enables depth processing for action in a visual form agnosic when binocular vision is unavailable. Neuropsychologia, 37: 1505-1510, 1999.

EFron R. What is perception? Boston Studies in Philosophy of Science, 4: 137-173, 1968.

FARAH MJ. Visual Agnosia: Disorders of Object Recognition and what they tell Us about Normal Perception. Cambridge: MIT Press, 1990

FARAH MJ and FeInBERG TE. Visual object agnosia. In TE Feinberg and MJ Farah. Behavioral Neurology and Neuropsychology. New York: McGraw Hill, 1997, pp. 239-244.

Franz VH, Gegenfurtner KR, Bulthoff HH and Fahle M. Grasping visual illusions: No evidence for a dissociation between perception and action. Psychological. Science, 11: 20-25, 2000.

GaFFAN D and HEYwood CA. A spurious category-specific visual agnosia for living things in normal human and nonhuman primates. Journal of Cognitive Neuroscience, 5: 118-128, 1993.

GaRdNer PL and Mon-Williams M. Monocular and binocular control of human interceptive movements. Experimental Brain Research, 136: 379-385, 2001.

GiBSON JJ. The Senses Considered as a Perceptual System. Boston: Houghton Mifflen, 1966.

Gold M, Adair JC, Jacobs DH and Heilman KM. Right-left confusion in Gerstmann's syndrome: A model of body centred spatial orientation. Cortex, 31: 267-283, 1995.

GoldsteIn EB. Sensation and Perception. Pacific Grove: Brooks/Cole, 1996.

GREGORY RL. Eye and Brain. New York: McGraw Hill, 1966.

GRUSSER O-J and LANDIS T. Visual Agnosias and other Disturbances of Visual Perception and Cognition. London: Macmillan Press, 1991.

HAFFENDEN AM and Goodale MA. The effect of pictorial illusion on prehension and perception. Journal of Cognitive Neuroscience, 10: 122-136, 1999.

HafFenden AM and Goodale MA. The dissociation between perception and action in the Ebbinghaus illusion: Non-illusory effects of pictorial cues on grasp. Current Biology, 11: 171$181,2001$.

HOCHBERG JE. Machines should see as people do, but must know how people see. Computer Vision, Graphics and Image Processing, 39: 221-237, 1987.

HuMPHREYS GW and RidDOCH MJ. To see but not to see: A Case Study of Visual Agnosia. London: Lawrence Earlbaum Associates., 1987.

JACKSON SR and SHAW A. The Ponzo illusion affects grip-force but not grip-aperture scaling during prehension movements. Journal of Experimental Psychology: Human Perception and Performance, 26: 418-423, 2000.

JolicoeUR P. The time to name disoriented natural objects. Memory and Cognition, 13: 289-303, 1985.

Julesz B. Foundation of Cyclopean Perception. Chicago: University of Chicago Press, 1971.

KwOK RM and BRADDICK OJ. Does the Titchener Circles illusion exert an effect on grasping two or three-dimensional targets? Neuropsychologia, 41: 932-940, 2003.

Lissauer H. Ein Fall von Seelenblindheit nebsteinen Betrag zur Theorie derselben. Archiv fur Psychiatrie and Nervenkrankheiten, 21: 222-270, 1890.

Marotta JJ, Behrmann M and Goodale MA. The removal of binocular cues disrupts the calibration of grasping in patients with visual form agnosia. Experimental Brain Research, 116: 113-121, 1997

MarotTa JJ, Desouza, JFX, HafFenden AM and Goodale MA. Does a monocularly presented size-contrast illusion influence grip aperture? Neuropsychologia, 36: 491-497, 1998.

MarotTa JJ and Goodale MA. The role of learned pictorial cues in the programming and control of grasping. Experimental Brain Research, 121: 465-470, 1998.

MCCARTHY RA and WARRINGTON EK. Visual associative agnosia: A clinico-anatomical study of a single case. Journal of Neurology, Neurosurgery and Psychiatry, 49: 1233-1240, 1986.

MCCARTHY RA and WARRINGTON EK. Cognitive neuropsychology: A clinical approach. San Diego: Academic Press, 1990.

MCCLOSKEY M and RAPP B. A visually based developmental reading deficit. Journal of Memory and Language, 43: 157181, 2000. 
McCloskey M, Rapp B, Yantis S, Rubin G, Bacon WF, Dagnelie G, Gordon B, Aliminosa D, Boatman DF, BAdecker W, Johnson DN, Tusa RJ and PAlMer E. A developmental deficit in localizing objects from vision. Psychological Science, 6: 112-117, 1995.

McKenNA P and WARRINGTON EK. Testing for nominal dysphasia. Journal of Neurology, Neurosurgery and Psychiatry, 43: 781788,1980

MARR D. Vision. San Francisco: Freeman, 1982

Milner AD and Goodale MA. The Visual Brain in Action. Oxford: Oxford University Press, 1995.

Mon-Williams $M$ and Dijkerman HC. The use of vergence information in the programming of prehension. Experimental Brain Research, 128: 578-582, 1999.

Mon-Williams M, Tresilian JR, Mcintosh RD and Milner AD. Monocular and binocular distance cues: insights from visual form agnosia I (of III). Experimental Brain Research, 139. 127-136, 2001

Otto-De Haart EG, Carey DP and Milne AB. More thoughts on perceiving and grasping the Müller-Lyer illusion. Neuropsychologia, 37: 1437-1444, 1999.

Penrose LS and Penrose R. Impossible objects: A special type of illusion. British Journal of Psychology, 49: 31-33, 1958.

Ratcliffe $G$ and Newcombe F. Object recognition: Some deductions from the clinical evidence. In AW Ellis (Ed), Normality and Pathology in Cognitive Function. London: Academic Press, 1982.

Riddoch MJ, Humphreys GW, Coltheart M and Funnell E. Semantic system or systems? Neuropsychological evidence re-examined. Cognitive Neuropsychology, 5: 3-25, 1988.

Rock I. Orientation and Form. New York: Academic Press, 1973

Sekuler R and Blake R. Perception. New York: McGraw Hill, 1990.

Servos P and Goodale MA. Monocular and binocular control of human interceptive movements. Experimental Brain Research, 119: 92-102, 1998.

Servos P, Goodale MA and JAKOBSON LS. The role of binocular vision in prehension. Vision Research, 32: 1513-1521, 1992.

SHEPARD RN and METZLER J. Mental rotation of three-dimensional objects. Science, 171: 701-703, 1971.

SHEPARD $S$ and Meltzer D. Mental rotation: Effects of dimensionality of objects and type of task. Journal of Experimental Psychology: Human Perception and Performance, 14: 3-1, 1988.

SHERIDAN J and HuMPHREYS GW. A verbal-semantic categoryspecific recognition impairment. Cognitive Neuropsychology, 10: $143-184,1993$

SNODGRASS JG and VANDERWART M. A standardized set of 260 pictures: Norms for name agreement, image agreement, familiarity, and visual complexity. Journal of Experimental Psychology: Human Perception and Performance, 6: 174-215, 1980.

Solms M, Kaplan-Solms K, Saling M and Miller P. Inverted vision after frontal lobe disease. Cortex, 24: 499-509, 1988

Solms M, Turnbull OH, Kaplan-Solms $\mathrm{K}$ and Miller P. Rotated drawing: The range of performance, and anatomical correlates, in a series of 16 patients. Brain and Cognition, 38: 358-368, 1998.

TARR MJ and BuLTHOFF HH. Image based object recognition in man, monkey and machine. In MJ Tarr and $\mathrm{HH}$ Bulthoff. Image based Object Recognition in Man, Monkey and Machine. Amsterdam: Elsevier Science Publishers, 1998, pp. $1-20$.

TEUBER H-L. Alteration of perception and memory in man. In L Weizkrantz. Analysis of Bevavioral Change. New York: Harper and Row, 1968.

Turnbull OH. Of two minds about two visual systems. Psyche, 5: 1-5, 1999.

Turnbull OH, Beschin N and Della Sala S. Agnosia for object orientation: Implications for theories of object recognition. Neuropsychologia, 35: 153-163, 1997.

Turnbull OH, Della Sala S and Beschin N. Agnosia for object orientation: Naming and mental rotation evidence. Neurocase, 8: 296-305, 2002

Turnbull OH and MCCARTHY RA. When is a view unusual? A single case study of orientation-dependent visual agnosia. Brain Research Bulletin, 40: 497-503, 1996a.

TurnBull $\mathrm{OH}$ and MCCARTHY RA. Failure to discriminate between mirror-image objects: A case of viewpointindependent object recognition? Neurocase, 2: 63-72, 1996b.

TURNBULL OH, LAWS KR and MCCARTHY RA. Object recognition without knowledge of object orientation. Cortex, 31: 387-395, 1995.

TURNBULL OH and LAwS KR. Loss of stored knowledge of object structure: Implications for 'category-specific' deficits. Cognitive Neuropsychology, 17: 365-389, 2000.

UNGERLEIDER LG and MishKIN M. Two cortical visual systems. In DJ Ingle, MA Goodale and RJW Mansfield (Eds), Analysis of Visual Behavior. Cambridge, MA: MIT Press, 1982, pp. 549586.

Warrington EK and James M. The Visual Object and Space Perception Battery. Thames Valley Test Company, 1991.

Young AW and DEREGOWSKI JB. Learning to see the impossible. Perception, 10: 91-105, 1981.

Oliver Turnbull, Centre for Cognitive Neuroscience, School of Psychology,University of Wales, Bangor, Wales, LL57 2AS, UK

e-mail: o.turnbull@bangor.ac.uk 